\title{
BIOPOLÍTICA: UM DIÁLOGO COM A(S) INFÂNCIA(S)
}

\author{
Monique Cristina Francener Hammes Schütz \\ Gicele Maria Cervi \\ Mirele Corrêa ${ }^{(*)}$
}

\section{INTRODUÇÃO}

O presente estudo problematiza a infância na sociedade contemporânea, reconhecendo esse período da vida como um dispositivo de controle sobre os corpos nessa sociedade caracterizada como Biopolítica. Trata-se de uma pesquisa qualitativa, bibliográfica, de cunho exploratório.

A infância evidencia-se na Modernidade, quando determinadas características universais da criança são percebidas e ela torna-se parte da população a ser medida e calculada, alvo de instituições e objeto de saber. No entanto as ideias sobre a infância alteram-se, seus discursos constituem práticas, ideias e ações voltadas às crianças que naturalizam os conceitos e camuflam as relações de poder, que se constituíram historicamente.

Por meio de estudos realizados acerca das obras de Michel Foucault e Gilles Deleuze, já não estamos mais vivenciando uma Sociedade Disciplinar, tal qual era evidenciada na Modernidade. As sociedades, com o passar do tempo vão se reformulando, se complementando, elas não se extinguem e deixam de ser. Contudo, estamos vivenciando hoje, conforme os autores, uma sociedade em tempos de Biopolítica, ou seja, onde o governo regulamenta a população através de um poder exercido sobre todos os aspectos da vida humana, gerando uma nova tecnologia política de dominação que se aplica aos corpos numeráveis que se constituem como problema econômico, político e social.

A Biopolítica procede por massificação da multiplicidade global, sendo a arte de governar, por meio de procedimentos destinados a dirigir a conduta dos homens (GADELHA, 2009).

\footnotetext{
${ }^{(*)}$ Monique C. F. Hammes Schütz. Graduada em Pedagogia da Universidade Regional de Blumenau (FURB, 2014). Mestranda do Programa de Pós-graduação do Mestrado em Educação (PPGE/FURB). Integrante do Grupo de Pesquisa Políticas de Educação na Contemporaneidade. Bolsista Capes. E-mail: moniquecfh@ hotmail.com.

Gicele M. Cervi. Possui graduação em Pedagogia pela Universidade do Vale do Itajaí (1988), mestrado em Educação pela Fundação Universidade Regional de Blumenau (1998) e doutorado em Ciências Sociais pela Pontifícia Universidade Católica de São Paulo (2010). Atualmente é professora do quadro da Universidade Regional de Blumenau (FURB). Professora do Mestrado em Educação (PPGE-FURB). E-mail: gicele.cervi@gmail.com.
}

Mirele Corrêa. Graduada em Pedagogia Universidade Regional de Blumenau (FURB). Mestranda do Programa de Pós-graduação do Mestrado em Educação (PPGE-FURB). Integrante do Grupo de Pesquisa Políticas de Educação na Contemporaneidade. E-mail: mirele_correa@yahoo.com.br. 
Foucault (1997, apud GADELHA, 2009, p. 121) considera a arte de governar como a "atividade de direção dos indivíduos ao longo de suas vidas. Colocando-os sob a autoridade de um guia responsável por aquilo que fazem e lhes acontece".

Sendo assim, a infância nesta sociedade se organiza sob novas bases, em que o objetivo do governo passa a ser a população, e as crianças passam a ser alvo privilegiado dessas operações de administração dos corpos, que visam uma gestão calculista da vida.

O trabalho estrutura-se em duas partes. Primeiro, discute-se o que é a Biopolítica e no segundo momento, problematiza-se os discursos sobre a infância nesta sociedade, que evidenciamse nas Diretrizes Curriculares Nacionais para a Educação Infantil.

\section{PARA INÍCIO DE CONVERSA: O QUE É BIOPOLÍTICA?}

O discurso da Biopolítica começou a ser considerado no final do século XIX e início do século XX. No campo acadêmico esses estudos acerca desse novo discurso social, iniciaram-se recentemente na década de 1990.

Por meio dos muitos estudos genealógicos realizados por Foucault na tentativa de compreender o funcionamento e o jogo de poder das sociedades desde a soberana à sociedade disciplinar, ele iniciou uma pesquisa que dava conta de compreender a próxima sociedade que viria ilustrar os novos tempos, denominada por ele de sociedade em tempos de Biopolítica.

Para compreendermos o que este novo conceito quer explicitar, temos que antes de tudo compreender que o tempo histórico, na qual fazemos parte, foi e é constantemente marcado por diversos processos de transformação. Michel Foucault em muitas de suas pesquisas focou seus estudos aos modos de vida marcados pelas sociedades soberana e disciplinar. Contudo, em seus escritos, deixou claro que o tempo da sociedade disciplinar estava acabando, e que Deleuze seria responsável por ilustrar a nova sociedade. Antes que nos atenhamos a estudar essas sociedades, devemos ressaltar que nenhuma sociedade acaba, se extingue, some. As sociedades se reinventam e se complementam. Por mais que as sociedades se modernizam, as marcas de cada uma delas ainda são visíveis e sensíveis (FOUCAULT, 2010).

A sociedade soberana evidencia-se por volta do século XVI. É marcada pelo Rei que sanciona as leis e os súditos obedecem. A justiça é feita por sua ordem e palavra, na qual manda executar, matar, todo aquele que infringir as regras. A disciplina e a moralidade eram internalizadas pelo medo de morrer, pois a morte estava visível aos olhos de todos. 
Entretanto, por volta do século XVII e XVIII, principalmente na Europa e nos Estados Unidos, a justiça penal vai se reformulando, aparece uma nova teoria da lei e do crime, uma nova justificação moral que dá ênfase à humanização e à definição do caráter essencialmente corretivo da pena. Desaparece o suplício, pois "a execução pública é vista então como uma fornalha em que se acende a violência" (FOUCAULT, 2010, p. 14). A punição deixa o campo da visibilidade e entra no campo da consciência abstrata, "[...] a certeza de ser punido é que deve desviar o homem do crime e não mais o abominável teatro" (FOUCAULT, 2010, p. 14, grifo nosso). O crime passa a ser vergonhoso, e a condenação passará a ser marcada no delinquente como um sinal negativo. $\mathrm{O}$ essencial agora é procurar corrigir, reeducar. A punição deve atingir mais a vida do que o corpo. Entra em cena, a prisão, que ostentará medidas de sofrimento físico, ou seja, um castigo incorporal, “pois não é mais o corpo, é a alma. À expiação que tripudia sobre o corpo deve suceder um castigo que atue, profundamente, sobre o coração, o intelecto, a vontade, as disposições" (FOUCAULT, 2010, p. 21).

[...] dar aos mecanismos da punição legal um poder justificável não mais simplesmente sobre as infrações, mas sobre os indivíduos; não mais sobre o que eles fizeram, mas sobre aquilo que eles são, serão, ou possam ser. [...] começam a julgar coisa diferente além dos crimes: a "alma" dos criminosos (p. 23).

Mudam-se os objetivos, muda-se a sociedade, para que a punição da alma aconteça, é necessário medidas de disciplinamento, medidas e técnicas adequadas de controle do indivíduo. Desta forma,

[...] viram-se aparecer técnicas de poder que eram essencialmente centradas no corpo, no corpo individual. Eram todos aqueles procedimentos pelos quais se assegurava a distribuição espacial dos corpos individuais (sua separação, seu alinhamento, sua colocação em série e em vigilância) e a organização, em torno desses corpos individuais, de todo um campo de visibilidade. [...] toda essa tecnologia que podemos chamar de tecnologia disciplinar do trabalho. Ela se instala já no final do século XVII e no decorrer do século XVIII. (FOUCAULT, 1999, p. 288).

Muitos fatores entraram em questão nos julgamentos, passou-se a avaliar as aspirações, os instintos, as enfermidades que levaram à realização do crime. A loucura passou a ser considerada, e com ela milhares de especialistas passaram a fazer parte do sistema penal, entre eles: psicólogos, psiquiatras, educadores, magistrados, etc. A prisão deixou de ser o único espaço de detenção, para dar lugar aos manicômios, hospitais de tratamento, etc.

Foucault assinala que antes de tudo devemos analisar os sistemas punitivos concretos como fenômenos sociais, e "mostrar que as medidas punitivas não são simplesmente mecanismos 
"negativos" que permitem reprimir, impedir, excluir, suprimir: mas que elas estão ligadas a toda uma série de efeitos positivos e úteis que elas têm por encargo sustentar". (FOUCAULT, 2010, p. 28).

Em nossas sociedades os sistemas punitivos devem ser analisados como uma economia política do corpo, mesmo não sendo aplicados castigos violentos no corpo físico, é sempre do corpo que se trata, da sua força, da sua utilidade, da sua docilidade, da sua repartição e submissão (FOUCAULT, 2010). Trabalha-se no corpo, para afetar a alma e o inconsciente.

Este investimento político do corpo está ligado, segundo relações complexas e recíprocas, à sua utilização econômica; é, numa boa proporção, como força de produção que o corpo é investido por relações de poder e de dominação; mas em compensação sua constituição como força de trabalho só é possível se ele está preso num sistema de sujeição (onde a necessidade é também um instrumento político cuidadosamente organizado, calculado e utilizado); o corpo só se torna força útil se é ao mesmo tempo corpo produtivo e corpo submisso. Essa sujeição não é obtida só pelos instrumentos da violência ou da ideologia; pode muito bem ser direta, física usar a força contra a força, agir sobre elementos materiais sem no entanto ser violenta [...] (p. 29).

Alguns desses sistemas de sujeição do corpo, como já vimos, foram produzidos pelas instituições escolares. Espaços inicialmente destinados a disciplinar o corpo, a moralizar os indivíduos às regras da sociedade e da religiosidade, a prepará-los mentalmente e fisicamente para suportar um sistema de produção, consumo e competitividade. Todas essas organizações técnicas pensadas na sujeição do corpo funcionam quase que como um saber e um controle das forças que vão muito além da capacidade de vencê-las, Foucault (2010) a chama de tecnologia política do corpo que começa aparecer na segunda metade do século XVIII. Esse poder perpetua pela vida de todos os indivíduos, transpassa todos os nossos meios relacionais e vivenciais, é uma tecnologia difusa, imperceptível, "impossível de localizá-la, quer num tipo definido de instituição, quer num aparelho de Estado" (FOUCAULT, 2010, p. 29), mesmo que saibamos que estes recorrem à ele, para se efetivar, se favorecer, utilizam aparelhos e instituições para colocar em jogo o que chama Foucault de microfísica do poder ou de Biopoder.

Esse conceito de biopoder é explicado por Foucault como uma nova técnica de poder, não disciplinar, que se utiliza de outros procedimentos e instrumentos não aplicados propriamente ao corpo, mas

a vida dos homens, ou ainda, se vocês preferirem, ela se dirige não ao homem-corpo, mas ao homem-vivo, ao homem ser vivo; no limite, se vocês quiserem, ao homem-espécie. Mais precisamente, eu diria isto: a disciplina tenta reger a multiplicidade dos homens na medida em que essa multiplicidade pode e deve redundar em corpos individuais que devem ser vigiados, treinados, utilizados, eventualmente punidos. E, depois, a nova tecnologia que se instala se 
dirige à multiplicidade dos homens, não na medida em que ela forma, ao contrário, uma massa global, afetada por processos como o nascimento, a morte, a produção, a doença, etc. [...] temos um segunda tomada de poder que, por sua vez, não é individualizante mas é massificante (FOUCAULT, 1999, p. 289).

O que se aplica em sala de aula é uma imposição de poder massificadora, generalizadora, é uma modulação da alma dos escolares, é um adestramento do corpo-mente dos indivíduos, uma forma de punição. O aparelho escolar é um dispositivo do biopoder. A escola que conhecemos hoje, a escola moderna, não existia na sociedade soberana, ela foi produzida, idealizada e funcionou na sociedade disciplinar, e por centenas de anos suas práticas foram voltadas para a produção de um corpo dócil, útil e por isso sistemático, robotizado, reprodutor. Contudo, a sociedade mudou, se reformulou. Não estamos mais vivendo numa sociedade disciplinar.

Por meio dos estudos acerca do biopoder, definidas no final do século XVIII, emerge não mais um estudo político do corpo humano, mas o que Foucault (1999) chamaria de "biopolítica" da espécie humana, e Deleuze - seu precursor - chamaria de Sociedade de Controle.

É certo que entramos em sociedades de "controle", que já não são exatamente disciplinares. Foucault é com freqüência considerado como o pensador das sociedades de disciplina, e de sua técnica principal, o confinamento (não só o hospital e a prisão, mas a escola, a fábrica, a caserna). Porém, de fato, ele é um dos primeiros a dizer que as sociedades disciplinares são aquilo que estamos deixando para trás, o que já não somos. Estamos entrando nas sociedades de controle, que funcionam não mais por confinamento, mas por controle contínuo e comunicação instantânea. (DELEUZE, 1992, p. 215).

Biopolítica caracteriza-se por um governo que regulamenta a população através de um poder exercido sobre todos os aspectos da vida humana, ou seja, o biopoder, gerando uma nova tecnologia política de dominação que se aplica aos corpos numeráveis que se constituem como problema econômico, político e social.

A biopolítica procede por massificação da multiplicidade global, sendo a arte de governar, por meio de procedimentos destinados a dirigir a conduta dos homens (GADELHA, 2009). Foucault (1997, apud GADELHA, 2009, p. 121) considera a arte de governar como a "atividade de direção dos indivíduos ao longo de suas vidas. Colocando-os sob a autoridade de um guia responsável por aquilo que fazem e lhes acontece".

Foucault (apud Deleuze, 1992) situou as sociedades disciplinares nos séculos XVIII e XIX, procedendo-as aos grandes meios de confinamento, em espaços fechados como na família, depois na caserna, nas fábricas, no hospital e na prisão. Foucault (apud Deleuze, 1992) analisou muito bem o projeto ideal dos meios de confinamento, visível especialmente na fábrica: concentrar; distribuir 
no espaço; ordenar no tempo; compor uma força produtiva. Entretanto, Foucault era ciente da transição deste modelo social, que sucedia a sociedade de soberania, e era ciente que a sociedade disciplinar também, iria transitar:

[...] as disciplinas, por sua vez, também conheceriam uma crise, em favor de novas formas que se instalavam lentamente e que se precipitariam depois da Segunda Guerra Mundial: sociedades disciplinares é o que já não éramos mais, o que deixávamos de ser. (DELEUZE, 1992, p. 220).

Tudo passa a entrar em crise, a sofrer mudanças necessárias, os discursos de reformas são generalizadas para a indústria, a escola, o hospital, a prisão. Para Deleuze (1992) instala-se uma nova força, na qual a sociedade de controle passa a substituir a disciplinar. Uma não é melhor ou pior do que outra, pois todas elas enfrentam as liberações e as sujeições (1992).

Na sociedade soberana tirava-se a vida, na disciplinar deixava-se viver para ser exemplo, na sociedade de controle interessa fazer viver, todos devem tolerar e dar chance. Todos devem participar, estar em constante movimento, num processo contínuo e permanente de atualização. Antes se procurava individualizar, agora se pretende tornar os indivíduos dividuais, divisíveis, pois nos tornamos amostras, dados, mercados ou bancos (DELEUZE, 1992).

A sociedade de controle pretende a todos controlar, de maneira que esse poder não possa ser visível, tudo anda ligeiramente, o tempo corre, não há tempo para reflexão, questionamento, são compromissos, trabalho, estudo, e nesse meio tempo o sistema flui continuamente.

Essa sociedade globalizada, informatizada, é o resultado de uma mutação do capitalismo que também, sofreu transformações. É o capitalismo do século XIX que se caracteriza em concentração. Concentração de produção e de propriedades, que acabam interferindo, ou melhor, nos sujeitando a esse novo sistema, a essa nova forma de viver.

É um capitalismo de sobre-produção. Não compra mais matéria-prima e já não vende produtos acabados: compra produtos acabados, ou monta peças destacadas. O que ele quer vender são serviços. E o que quer comprar são ações. Já não é um capitalismo dirigido para a produção, mas para o produto, isto, é, para a venda ou para o mercado. Por isso ele é essencialmente dispersivo, e a fabrica cedeu lugar à empresa. A família, a escola, o exercito, a fábrica não são mais espaços analógicos distintos que convergem para um proprietário, Estado ou potência privada, mas são agora figuras cifradas, deformáveis e transformáveis, de uma mesma empresa que só tem gerentes. [...] As conquistas de mercado se fazem por tomada de controle e não mais por formação de disciplina, por fixação de cotações mais do que por redução de custos, por transformação do produto mais do que por especialização da produção. [...] O serviço de vendas tornou-se o centro ou a "alma" da empresa. [...] O marketing é agora o instrumento de 
controle social, e forma a raça impudente de nossos senhores. [...] O homem não é mais o homem confinado, mas o homem endividado. (DELEUZE, 1992, p. 223-224).

O que move uma sociedade, todas essas relações de poder na qual somos sujeitados, a essa organização de vida na qual fazemos parte, é devido aos ideais e objetivos dos jogos de poder que se quer efetivar, que se quer afirmar. A obrigatoriedade da escola, a necessidade de emprego, a moda, o lazer, a constituição de família, a necessidade religiosa, o Senso, a segurança pública, o Sistema Único de Saúde (SUS), o Bolsa Família, o Índice de Desenvolvimento da Educação Básica (Ideb), a recuperação de presidiários, a inclusão de deficientes nas escolas e no mercado de trabalho, as apelações de educação e formação, as estatísticas, o estatuto social da infância, enfim, todos esses programas e discursos políticos que nos fazem acreditar que tudo está ao nosso favor, ao nosso benefício, que somos sujeitos de direitos, de autonomia e criticidade, são programas que mais do que isso, nos regulam, nos controlam, nos submetem, nos sujeitam, nos cegam. É um jogo político, que se utilizam de dispositivos para manipular a população, para nos fazer andar conforme seus interesses, e no caso dessa sociedade o interesse está voltado para o capitalismo, o lucro e o consumo as principais peças que fazem funcionar esse grande sistema.

"A biopolítica lida com a população, e a população com o problema político, como problema a um só tempo científico e político, como problema biológico e como problema de poder" (FOUCAULT, 1999, p. 293). A biopolítica trata de mecanismos reguladores da população, na tentativa de fixar um equilíbrio, de otimizar. Mecanismos disciplinares destinados a maximizar forças e a extraí-las. A biopolítica atua com um poder contínuo sobre os indivíduos, é um poder que faz viver, diferente da sociedade soberana que fazia morrer e deixava viver (FOUCAULT, 1999). A biopolítica é uma ação silenciosa do poder que cega os indivíduos fazendo-os aceitar o que lhes é imposto, ou que simplesmente inibe seu ato crítico acerca do funcionamento das coisas que o cerca e que o constitui, e esta é a principal arma dessa maquinaria, implica em um poder que não mais "faz viver e deixa morrer", mas num poder que faz tão bem as pessoas viverem que se consegue fazê-las viver no mesmo momento em que elas deveriam, biologicamente, estar mortas há muito tempo (FOUCAULT, 1999), ou seja,

Agora que o poder é cada vez menos o direito de fazer morrer e cada vez mais o direito de intervir para fazer viver, e na maneira de viver, e no como da vida, a partir do momento em que, portanto, o poder intervém sobretudo nesse nível para aumentar a vida, para controlar seus acidentes, suas eventualidades, suas deficiências, daí por diante a morte, como termo da vida, é evidentemente o termo, o limite, a extremidade do poder (p. 296, grifo do autor). 
Esse poder garante a vida, garante a segurança, garante a saúde, garante direitos. Contudo é um poder "oculto", que nos faz crer ser participativos, democráticos, autônomos, livres, quando na verdade estamos sempre sob controle, uma vez que estamos sempre e cada vez mais escolarizados.

Estar na escola é garantia de vida, é uma forma de segurança para nós e para o Estado. Estar na escola é participar, é estar incluído, é avaliar, ser avaliado, se autogestionar, por um tempo cada vez maior e cada vez mais cedo. Por isso a escola invade a infância, se apropria dessa etapa da vida, institucionaliza esse período determinando especificidades, condutas, comportamentos. A infância agora passa a ser alvo desse biopoder, para que desde muito cedo essa criança passe a ser governada, controlada, regulada.

O próximo capítulo buscará fazer essa relação da infância que agora é pensada dentro dos moldes da Biopolítica e para evidenciar que essa infância passa a ser concebida diferente do que era nas outras sociedades, traremos algumas leis das Diretrizes Curriculares Nacionais da Educação Infantil para ilustrar esse tempo.

\section{A BIOPOLÍTICA DA INFÂNCIA}

A forma como se percebe a criança, não é eterna e nem natural, as alterações que as figuras de criança têm sofrido no espaço e no tempo apontam seu caráter sócio-histórico. As transformações que afetaram a percepção da criança e da infância moderna estiveram intimamente ligadas aos modos de alteração de socialização (VARELA; ALVARES-URIA, 1991).

A entrada das crianças na história é um fato recente. O mérito desde trabalho pioneiro cabe ao historiador Philippe Ariès ao ter inaugurado uma nova compreensão acerca da infância:

[...] situando-a como um acontecimento caracteristicamente moderno, produto de uma série de condições que se conjugam e que estabelecem novas possibilidades de compreensão de um fenômeno que antes de uma realidade biológica, como se quis fazer crer, é um fato cultural por excelência. Lançar um olhar sobre as crianças, circunscrever o âmbito das experiências que lhes são próprias em cada idade, descrever os cuidados de que elas devem ser objeto, estabelecer critérios para julgar de seu desenvolvimento sadio, de sua normalidade, das operações necessárias para garantir sua transformação em cidadãos úteis e ajustados à ordem social e econômica vigente tornam-se preocupações sociais relevantes apenas muito recentemente. (BUJES, 2000, p. 26).

Segundo Bujes (2000), Ariès contribuiu por mostrar as mudanças de atitudes e os sentimentos diante das crianças, que acabaram por se incorporar às mentalidades, fazendo emergir 
um conceito de infância que se consolidou por volta do século XVII e que se difundiu, a partir do século XVIII, dando a esta fase da vida humana um destaque até aí jamais alcançado.

$\mathrm{Na}$ Idade Média a criança ao adquirir alguma desenvoltura física, era misturada aos adultos, partilhando de seus trabalhos e jogos, transformava-se em homem jovem, sem passar pelas etapas de juventude. Para tanto, a transmissão dos valores, dos conhecimentos e a socialização da criança, não era asseguradas e nem controladas pela família, mas eram garantidas pela convivência com os adultos, ajudando a fazer as coisas as quais devia aprender (ARIÈS, 1981).

Segundo Ariès (1981) a passagem da criança pela família e pela sociedade era muito breve e insignificante. Restringia-se aos primeiros anos de vida, em que existia um sentimento superficial de "paparicação", as pessoas se divertiam com as crianças. Se esta viesse a morrer, alguns ficavam desolados, mas a regra geral era não dar muita importância, pois logo outra criança a substituiria. Depois deste tempo era comum que a criança passasse a viver em outra casa, que não a de sua família.

A família na Idade Média tinha por incumbência: a conservação dos bens, a prática comum de um ofício, a ajuda mútua quotidiana num mundo em que um homem e uma mulher isolados não poderiam sobreviver, não se tinha função afetiva. "O sentimento entre os cônjuges, entre os pais e filhos, não era necessário à existência nem ao equilíbrio da família: se ele existisse, tanto melhor" (ARIÈS, 1981, p. 11).

As trocas afetivas e as comunicações sociais eram realizadas fora da família, com vizinhos, amigos, amos e criados, crianças e velhos, mulheres e homens, em que a inclinação se podia manifestar mais livremente (ARIÈS, 1981).

A partir do século XVII, duas abordagens distintas alteram o estado do lugar assumido pela criança e pela família. Primeiramente, a escola substitui a aprendizagem como meio de educação. A criança deixa de ser misturada aos adultos e de aprender a vida diretamente, através do contato com eles. A criança passa a ser separada dos adultos numa espécie de quarentena, que segundo Ariès (1981) foi a escola, o colégio, iniciando-se um processo de enclausuramento das crianças, ao qual se dá o nome de escolarização.

A segunda abordagem corresponde aos movimentos de moralização dos homens promovidos pelos reformadores católicos e protestantes ligados à Igreja, às leis e ao Estado, com a cumplicidade sentimental das famílias. A família torna-se um lugar de uma afeição necessária, devido principalmente a importância que se passou a atribuir a educação. Os pais além de estabelecer os filhos em função dos bens e da honra, passam a interessar-se pelos seus estudos e 
acompanhar com solicitude. Por tanto, a família passa a organizar-se em torno da criança e a lhe dar tal importância, que segundo Ariés (1981):

A criança saiu de seu antigo anonimato, que se tornou impossível perdê-la ou substituí-la sem uma enorme dor, que ela não pode mais ser reproduzida muitas vezes, e que se tornou necessário limitar seu número para melhor cuidar dela. (p.12).

A escola e o colégio, na Idade Média, tornaram-se o meio de isolar cada vez mais as crianças, durante um período de formação moral e intelectual, de adestrá-las, por meio de disciplina autoritária, separando-as da sociedade dos adultos (ARIÈS, 1981).

A partir do século XVIII estabelece-se um novo lugar para a infância, na nova paisagem social, mas também nos novos raciocínios populacionais que se consolidam (BUJES, 2000).

Mudam-se as relações entre adultos e crianças, numa sociedade que se organiza sob novas bases, segundo Bujes (2000), a partir dos estudos de Foucault, pode-se afirmar que o poder soberano perde a sua potência e é substituído por uma nova forma de governar. A partir de um grande aumento populacional, expansão da base monetária e um notável aumento da produção agrícola, emerge o problema da população que tem conexão estreita com o "desbloqueio da arte de governar". O modelo da família que orientava a arte de governo perde sua potência. O objetivo do governo passa a ser a população. É preciso gerir a vida dos indivíduos, agir diretamente sobre a população: estimular ou bloquear a taxa de natalidade, prevenir a mortalidade, controlar os fluxos populacionais, entender a população como sujeito de necessidades e aspirações. A família passa a se constituir em instrumento privilegiado para o governo das populações (BUJES, 2000).

O poder soberano se exercia pela ameaça da morte, mas a partir das profundas transformações, altera-se, e o direito à vida se impõe. É preciso nela investir e serão os corpos dos indivíduos os novos alvos do poder. Exercer-se-á em duas direções: a do corpo máquina e a do corpo espécie. É preciso adestrar os corpos, torná-los dóceis e úteis, mas ao mesmo tempo, garantir sua integração em sistemas de controle eficazes e econômicos. No entanto, o poder necessita também exercer-se sobre o corpo enquanto suporte de processos biológicos. Há que garantir a vida, a saúde, a proliferação da espécie (BUJES, 2000). Estabelecem-se intervenções e controles para regular tais processos, e as condições para fazê-los variar: "as disciplinas do corpo e as regulações da população constituem os dois polos em torno dos quais se desenvolveu a organização do poder sobre a vida". (FOUCAULT, 1997, p. 131).

Para Bujes (2000) as crianças passam a ser alvo privilegiado destas operações de administração dos corpos, que visam uma gestão calculista da vida: tornam-se objeto de operações 
políticas, de intervenções econômicas, de campanhas ideológicas de moralização e de escolarização, de uma intervenção calculada.

Neste momento, adulto e criança se diferenciam e se distanciam. Esta operação constitui a justificativa para a intervenção familiar e para a prática da educação institucionalizada. É preciso garantir o mito da inocência da infância e inseri-la em processos de controle e regulação cada vez mais sofisticados (BUJES, 2000).

Portanto, é na Modernidade que a criança se torna parte da população a ser medida, calculada, ordenada e produziu-se um crescente conhecimento sobre a mesma, tornando-se alvo de algumas instituições e objeto de saber (BUJES, 2003).

É neste contexto que surge a ideia de infância, tendo como berço a escola e a família (MÜLLER, 2006). Para Bujes (2003), esta ideia de que a infância foi descoberta pressupõe que certas características universais da criança foram percebidas em determinado momento histórico, de reflexão e atividade cientifica. As palavras usadas para descrever as crianças e as infâncias são arbitrárias e históricas. Os discursos de investigação científica sobre as mesmas são produtos das relações entre a verdade e o poder. Para tanto, torna-se mais apropriado falar em invenção da infância moderna (BUJES, 2003).

A vida e a infância são organizadas a partir do saber médico, são classificadas, repartidas em etapas e reconhecidas de atributos comuns, que chancela e autoriza procedimentos, saberes, agentes, materiais, métodos e instituições especializadas em cada uma das etapas da vida (GONDRA, 2010). Segundo Varela e Uria (1991) esses estágios, capacidades lógicas e psicológicas criam uma espécie de infância universal que se sobrepõe às condições sociais e culturais.

Gondra (2010) expõe que nos debates sobre a infância reconhece-se um traço comum: um período da vida humana, constituída por um sistema normativo, características, formas, competências e funções, precisas ou fluídas, ancoradas em sistema de ordenação, que cada grupo social relaciona ao seu sistema valorativo. Contrapondo-se, Gondra (2010) propõe tratar a infância como algo forjado, interessando explorar o próprio processo que termina por delinear a força e os limites daquilo que o termo pretende descrever.

Ao tratar da infância como algo forjado, Gondra (2010) propõe analisar alguns aspectos como ferramenta para pensar o termo infância, associando o "surgimento" da infância à instituição e legitimação de uma concepção de vida recortada em etapas que se apresentam nas Diretrizes Curriculares Nacionais para Educação Infantil (DCNEI, 2009). 
Primeiramente, Gondra (2010) expõe que a partir do saber médico organizou-se uma representação da vida e infância, tais como: alimentação, vestimentas, tipos de atividades, desenvolvimento físico, intelectual e moral, demonstrando como o campo pedagógico é invadido pelo saber médico, mesmo sendo distintos, partilham de tais representações. Ao privilegiar este discurso médico, sublinha-se o aspecto da vida segmentada, que articula a outros elementos, como configuração das famílias, funções exercidas por homens, mulheres e crianças. Como é possível observar DCNEI (2009) que define quem é esta criança:

Sujeito histórico e de direitos que, nas interações, relações e práticas cotidianas que vivencia, constrói sua identidade pessoal e coletiva, brinca, imagina, fantasia, deseja, aprende, observa, experimenta, narra, questiona e constrói sentidos sobre a natureza e a sociedade, produzindo cultura (DCNEI, 2009, p. 12).

E propõe um currículo específico para promover o desenvolvimento integral da criança de 0 a 5 anos de idade, composto por

\begin{abstract}
conjunto de práticas que buscam articular as experiências e os saberes das crianças com os conhecimentos que fazem parte do patrimônio cultural, artístico, ambiental, científico e tecnológico [...] que deve ter como objetivo garantir à criança acesso a processos de apropriação, renovação e articulação de conhecimentos e aprendizagens de diferentes linguagens, assim como o direito à proteção, à saúde, à liberdade, à confiança, ao respeito, à dignidade, à brincadeira, à convivência e à interação com outras crianças. (DCNEI, 2009, p. 12-18).
\end{abstract}

A Educação Infantil caracteriza-se como espaços institucionais não domésticos, com obrigatoriedade de matrícula a crianças que completam 4 ou 5 anos até o dia 31 de março, com as jornadas oferecidas em tempo parcial de no mínimo quatro horas diárias ou em tempo integral, de sete ou mais horas diárias (DCNEI, 2009).

Tais aspectos relacionam-se a escola e a casa como instituições que reforçam o caráter estratificado sobre vida, definindo um tempo de competência sobre a vida, que seria responsabilidade da casa e outro da escola. O Estado, interessado em disciplinar os corpos e as populações, como forma de se legitimar e de se reproduzir, faz da escola uma agência talhada para agir sobre essas formas, assim como o alargamento do tempo escolar, com a entrada da criança cada vez mais precoce, sugere um alargamento da disciplina e do biopoder (GONDRA, 2010).

As reconfigurações do mundo, da casa e do trabalho, exigem novas necessidades, a Educação Infantil, contribui, também, para a institucionalização maciça da criança. As crianças passam a ser descritas em termos de população, um corpo quantificável, localizável, mensurável. 
Logo, pensar a infância como população é pensar medidas globais para essa massa, que exigirá práticas governamentais dos aspectos próprios a esse conjunto de seres (GONDRA, 2010).

Evidencia-se nas DCNEI (2009) propostas pedagógicas distintas de reconhecimento da diversidade desta população como: culturas africanas, afro-brasileiras, indígenas e de infâncias do campo.

A articulação do saber e poder emergem e terrificam determinadas ideias, como a ideia de infância e das instituições que passam a sustentar determinadas práticas voltadas para este segmento da vida (GONDRA, 2010). Não apenas a escola, mas outras instituições passam a pensar em atividades específicas, aulas extra curriculares: dança, cursos de línguas, pintura, esportes, canto, instrumentos musicais, entre outros, ampliando ainda mais a carga horária das crianças. Há um investimento sobre a vida, para mais tarde se ter o produto, o retorno de tal investimento. É um controle, um governamento, um modo de ação que não age diretamente sobre os outros, mas que age sobre sua própria ação. É o modo como o poder conduz condutas. Essas são exercidas em redes, em vários pontos do aspecto social (BUJES, 2003). E podem ser observadas nos discursos sobre a criança e a infância, pois constroem e moldam a maneira como pensamos, agimos e nos comportamos em relação a elas (JAEHN; FERREIRA, 2012).

Portanto, as formulações de criança e infância não são isentas de poder, pelo contrário, são efeitos dos jogos de poder e de vontade de saber. Um poder que seduz e que acumplicia.

\section{FINALIZANDO}

O que viemos estudando até aqui, é que as relações e disputas de força e poder eram há muitos anos atrás mantidas por meio de guerras e disputas bélicas travadas entre os povos e Governos. Entretanto, as sociedades mudaram e se modernizaram, a política usa outras armas para se efetivar. Na sociedade atual, a Biopolítica usa de diversos outros dispositivos para impor seu poder, Foucault, considera que a política é a guerra continuada por outros meios (1999). E realmente é, pois usa principalmente de meios para controlar e regular a sociedade, fazendo-a caminhar por percursos que vem de acordo com seus interesses.

Uns dos meios para regular a vida é através dos discursos voltados para a infância. Buscamos entender que a infância que foi criada no início do século XVII, já não é mais a mesma que se evidencia hoje na sociedade de Biopolítica, ela sofreu e sofre modulações constantemente para estar sempre se reafirmando. A infância que conhecemos hoje foi construída, e pretende constituir um sujeito (a criança) com determinadas características universais, instituições e práticas 
voltadas para este segmento da vida, classificadas e repartidas em etapas, reconhecidas de atributos comuns, como: procedimentos, saberes, agentes, materiais, métodos e instituições especializadas.

Portanto, percebe-se que ao longo da história as crianças sempre existiram, como seres biológicos de geração jovem, mas nem sempre houve a infância como categoria social de estatuto próprio. Com o passar dos tempos os discursos sobre a infância alteram-se. É preciso problematizar sobre esses discursos, pois constituem as práticas voltadas às crianças, moldando o nosso pensar, ideias e ações. Realiza-se um controle sobre os discursos, que levam a naturalização dos conceitos e camuflam as relações de poder que se constituíram historicamente.

Por fim, se a Biopolítica se caracteriza por um governo que regulamenta a população através de um poder exercido sobre todos os aspectos da vida humana, então, a infância se constitui como um desses aspectos.

\section{REFERÊNCIAS}

ARIÈS, P. História social da criança e da família. 2. ed. Rio de Janeiro: Zahar Editores, 1981.

BRASIL. MEC/SEB. Resolução 05/2009. Diretrizes curriculares nacionais para a educação infantil. Diário Oficial da União. Brasília: MEC/CEB, 10 dez. 2009, Seção 1.

BUJES, M. I. E. Alguns apontamentos sobre as relações infância/poder numa perspectiva foucaultiana. In: ANPEd. Anais da $26^{\mathbf{a}}$ Reunião Anual... Poços de Caldas (MG); Anped, 2003. p. 1-13.

. O fio e a trama: as crianças nas malhas do poder. Educação e Realidade, v. 25, n. 1, p. 25-44, jan./jun. 2000.

CERVI, G. M. Política de gestão escolar na sociedade de controle. 2010. 245 f. Tese (Doutorado em Ciências Sociais) - Pontifícia Universidade Católica de São Paulo, São Paulo, 2010.

DELEUZE, G. (1925-1995). Controle e Devir. In: Conversações, 1972-1990. Trad.: Peter Pál Pelbart. Rio de Janeiro: Ed. 34, 1992, p. 232. (Col. TRANS.)

FOUCAULT, M. Em defesa da sociedade: Curso no Collège de France (1975-1976). Trad.: Maria Ermantina Galvão. São Paulo: Martins Fontes, 1999. p. 382.

História da sexualidade I: a vontade de saber. Rio de Janeiro: Graal, 1997.

Vigiar e Punir: Nascimento da Prisão. Trad.: Raquel Ramalhete. 38. ed. Petrópolis, RJ: Vozes, 2010.

GADELHA, S. Biopolítica, governamentalidade e educação. Introduções e conexões, a partir de Michel Foucault. Belo Horizonte: Autêntica Editora, 2009. (Educação: Experiência e Sentido.)

GONDRA, J. G. A emergência da infância. Educação em Revista. Belo Horizonte, v. 26, n. 01, p. 195-214, abr. 2010.

JAEHN, L.; FERREIRA, M. S. Perspectivas para uma história do currículo: as contribuições de Ivor Goodson e Thomas Popkewitz. Currículo sem Fronteiras, v. 12, n. 3, p. 256-272, set./dez. 2012.

MÜLLER, F. Infâncias nas vozes das crianças: culturas infantis, trabalho e resistência. Educ. Soc., Campinas, vol. 27 , n. 95, p. 553-573, maio/ago. 2006.

VARELA, J.; ALVEREZ-URIA, F. Arqueologia da escola. Madrid: Las ediciones de La Piqueta, 1991. 


\section{BIOPOLITICS: A DIALOGUE WITH CHILDHOOD}

\section{RESUMO}

Esta pesquisa é caracteriza-se como sendo qualitativa, bibliográfica, que tem por objetivo problematizar a infância na sociedade contemporânea, reconhecendo esse período da vida como dispositivo de controle sobre os corpos que evidenciam-se nas Diretrizes Curriculares Nacionais para a Educação Infantil. Os principais autores que fundamentam esta pesquisa são Foucault, Deleuze, Bujes e Gondra. Por meio de uma trajetória histórica desde a Sociedade Soberana passando pela Disciplinar, a pesquisa busca conceituar a atual sociedade de Biopolítica e evidencia que as formulações de infância não são isentas de poder, são efeitos dos jogos de poder e vontades de saber que controlam e regulam condutas.

Palavras-chave: Sociedade. Biopolítica. Infância. Poder.

\section{ABSTRACT}

This research is characterized as qualitative, literature, which aims to discuss childhood in contemporary society, recognizing this period of life as a control device on the bodies that show up in the National Curriculum Guidelines for Early Childhood Education. The main authors who support this research are Foucault, Deleuze, and Bujes Gondra. Through a historical trajectory from the Society Sovereign through the Discipline, the research seeks to conceptualize the current society of Biopolitics and evidence that childhood formulations are not without power, are effects of power games and wants to know that control and regulate pipelines.

Key words: Society. Biopolitics. Childhood. Power.

Submetido fev. 2016

Aprovado maio 2016 